\title{
CONFLITOS TERRITORIAIS E IMPACTOS SOCIOAMBIENTAIS NA BACIA HIDROGRÁFICA DO RIO PRETO, MARANHÃO - BRASIL
}

\section{TERRITORIAL CONFLICTS AND SOCIO-ENVIRONMENTAL IMPACTS IN RIO PRETO WATER BASIN, MARANHÃO - BRAZIL}

\author{
Idevan Gusmão Soares \\ Universidade Estadual do Maranhão, Programa de Pós-Graduação em Geografia, Natureza e \\ Dinâmica do Espaço, São Luís, MA, Brasil. \\ idevanoficial@gmail.com \\ Luiz Carlos Araujo dos Santos \\ Universidade Estadual do Maranhão, Programa de Pós-Graduação em Geografia, Natureza e \\ Dinâmica do Espaço, São Luís, MA, Brasil. \\ luisantos@professor.uema.br \\ Silas Nogueira de Melo \\ Universidade Estadual do Maranhão, Programa de Pós-Graduação em Geografia, Natureza e \\ Dinâmica do Espaço, São Luís, MA, Brasil. \\ silasmelo@professor.uema.br \\ Regina Célia de Oliveira \\ Universidade Estadual de Campinas, Departamento de Geografia. Programa de Pós-Graduação \\ em Geografia, Campinas, São Paulo, Brasil. \\ reginacoliveira@ige.unicamp.br
}

\section{Resumo}

Tendo em vista os diferentes conflitos de uso e ocupação das terras identificados na bacia hidrográfica do Rio Preto/Maranhão, associado de forma mais específica ao modelo de apropriação do espaço assistido entre a população camponesa e a crescente atividade das indústrias de agronegócios, presentes na área de estudo, direcionamos as discussões para a apresentação dos principais impactos ambientais vinculados a atividade industrial na bacia. Para tanto elegemos como procedimentos de investigação, a pesquisa bibliográfica, trabalho de campo e análises estatísticas com o uso de operações de geoprocessamento para confecção de mapas temáticos, recorrendo-se ao Sistema de Informação Geográfica (SIG). Os resultados apontam que os embates que se materializam na área de estudo estão diretamente ligados com a reprodução ampliada do capitalismo e que, nas últimas duas décadas, os municípios de Urbano Santos, Santa Quitéria do Maranhão e Belágua se destacaram com maior número de conflitos por terra. Concluímos que o modelo de uso das terras assistidos na área de estudo, ao não considerar a relação de fragilidade dos sistemas naturais, altera de forma significativa a estabilidade de sistemas frágeis como o bioma Cerrado, comprometendo não apenas a permanência do próprio sistema natural, como a subsistência da população camponesa que utiliza-se desse bioma como parte de sua sobrevivência. Desta forma, o presente artigo nos elucida de que forma os atritos 
acontecem, nos dando subsídios para elaboração de políticas públicas de prevenção a conflitos territoriais e diminuição de impactos ambientais.

Palavras-chave: Camponês. Agronegócio. Conflitos Territoriais. Impactos Socioambientais.

\begin{abstract}
Given the different conflicts of land use and occupation present in the Rio Preto/ Maranhão river basin, more specifically associated with the model of assisted space appropriation between the peasant population and the growing activity of the agribusiness industries present, we directed the discussions to the presentation of the main environmental impacts related to the industrial activity present in the basin. So, we chose as research procedures the literature review, fieldwork and statistical analysis using geoprocessing operations to make the map of conflicts in the water basin, using the Geographic Information System (GIS). The results show that the conflicts that materialize in the study area are directly related to the expanded reproduction of capitalism and that, in the last two decades, the municipalities of Urbano Santos, Santa Quiteria do Maranhão and Belagua stood out with the highest number of conflicts. We conclude that the landuse models in the study area, by not considering the fragility relationship of natural systems, significantly changes the stability of fragile systems such as the Cerrado biome, compromising not only the permanence of the natural system itself but also the subsistence of the peasant population that uses this biome as part of their survival. Thus, the present article sheds light on how conflicts occur, giving us subsidies for the elaboration of public policies for the prevention of territorial conflicts and the reduction of environmental impacts.
\end{abstract}

Keywords: Peasant. Agribusiness. Territorial Conflicts. Socio-Environmental Impacts.

\title{
Introdução
}

O presente artigo apresenta considerações sobre as recentes atividades econômicas desenvolvidas nos municípios que são banhados pela bacia hidrográfica do Rio Preto, Maranhão e seus impactos que atingem tanto o meio social como o meio natural. Atividades estas, ligadas à produção em grande escala como o Eucalipto para produção de papel e celulose, produção de carvão vegetal para atender a indústria siderúrgica e a produção da soja que vem se intensificando nesta região para atender os mercados externos e que provocam impactos nas comunidades tradicionais ali existentes, assim como para a natureza que é altamente afetada pela exploração intensiva de seus recursos. 
Nesta análise, destacaremos a territorialização da sojicultora nesta porção do território maranhense, sua viabilização e potencialização por intermédio das políticas desenvolvimentistas implantadas pelas diferentes escalas de governo, bem como as causas e consequências dos conflitos entre o agronegócio e a agricultura tradicional. A atividade ligada ao cultivo da soja no Maranhão ganha dimensão a partir da década de 1990, dando uma nova dinâmica ao território. Todavia, este território já detém outros sujeitos territorializados que moldaram a localidade segundo seus costumes, tradições, cultura e identidade. Embora a atividade dê uma nova direção ao setor produtivo, em escala econômica, com o aumento da produção de bens a partir da monocultura da soja, esta atividade produz riqueza, mas também produz desigualdades, pois a produção capitalista no campo não valoriza os laços culturais e afetivo preexistentes no território, ou seja, valorizam apenas os valores materiais e de produção ou tão somente algo que vem agregar e ampliar seu potencial produtivo.

Diante do exposto, o objetivo do trabalho foi realizar uma análise dos conflitos territoriais e os impactos ambientais decorrentes das agroindústrias que se estabeleceram nos municípios banhados pela bacia hidrográfica do Rio Preto, Maranhão.

$\mathrm{O}$ artigo encontra-se estruturado além da introdução, considerações finais e referências, em procedimentos metodológicos, contextualização da área de estudo, territorialização das agroindústrias na Mesorregião Leste Maranhense, causas e consequências dos conflitos territoriais na bacia hidrográfica do Rio Preto-MA, e resistência camponesa.

\section{Procedimentos metodológicos}

Para alcance do objetivo proposto, realizamos os seguintes procedimentos: revisão bibliográfica sobre temas específicos tais como impactos da expansão do agronegócio, territorialização, conflitos territoriais e violência no campo, dando subsídios teóricos a construção da leitura dos principais temas que subsidiaram a temática em análise; trabalhos de campo, na totalidade da área de estudo tendo como objetivos principais o reconhecimento da área-objeto e averiguar com maior critério a produção cartográfica, para tanto, foram realizados nos dias 29, 30 de junho e 01 de julho de 2018, assim como entre os dias 18 a 21 de abril de 2019 trabalhos de campo na área de pesquisa 
considerando o seguinte roteiro de atividades: observação dos elementos direto do espaço geográfico, seguida de registros fotográficos, verificação dos tipos de uso da terra e as condições ambientais da bacia.

A partir da bibliografia e observações de campo, verificamos que nos municípios abrangidos pela bacia do Rio Preto existem conflitos por terra (PAULA ANDRADE, 2011, 2012; RIBEIRO JÚNIOR; OLIVEIRA; COSTA, 2014). Por esse motivo produzimos um mapa temático de conflitos por terra da área de pesquisa, levando-se em consideração a escala temporal que vai de 2000 a 2018.

A partir das informações do Caderno Anual de Conflitos no Campo publicado pela Comissão Pastoral da Terra (2000-2018), foram ponderados, agrupados e representados na forma de polígonos os dados referentes a quantidade de conflitos na área de estudo. Foram considerados na análise e representação o total de conflitos que ocorreram nos últimos 19 anos no Maranhão sendo organizados na forma de planilhas do Microsoft Office Excel. Para cada município maranhense foi inserido sua respectiva quantidade de conflitos anuais, ou seja, foi afixado o quantitativo do ano 2000 até 2018. Na planilha foi realizada a operação de somatória de todos os conflitos de 2000 a 2018 para cada município, identificando-se nessa operação o total acumulado de conflitos por município.

A planilha contendo o total de conflitos foi exportada no formato CSV (separado por vírgula) e em seguida foi importada para o Sistema de Informação Geográfica (SIG) Quantum GIS, juntamente com a malha municipal do Maranhão (IBGE, 2017) e o limite da bacia hidrográfica. No SIG procedeu-se a união da planilha com a malha municipal, e posteriormente, realizou-se a operação de recorte (clip) dos municípios tendo como camada de corte o limite da bacia. Com esses procedimentos obteve-se a representação cartográfica da quantidade de conflitos por terra dos municípios que são abrangidos pela área de estudo.

Também foi produzido o mapa do total de famílias assentadas dos municípios banhados pela bacia. Para este fim, utilizou-se os dados de assentamentos de reforma agrária do DATALUTA, estes dados foram disponibilizados no formato de planilha do Excel, são informações compiladas sobre os assentamentos dos municípios das unidades da federação, no entanto, utilizou-se as informações referentes ao estado do Maranhão no período de tempo que vai de 1971 a 2015. 
Na planilha foi realizada a compilação das informações dos municípios que são abrangidos pela bacia e em seguida realizou-se a somatória do total de famílias assentadas por município. Posteriormente, procedeu-se os mesmos processos para a obtenção do mapa de conflitos por terra, a saber: exportação para o formato CSV (separado por vírgula); união da planilha com a malha municipal; recorte dos municípios tendo como camada de corte o limite da bacia.

\section{Contextualização da área de estudo}

A bacia hidrográfica do Rio Preto está localizada na região nordeste do estado do Maranhão e ocupa uma área de 5.235,63 $\mathrm{km}^{2}$. Afluente da bacia hidrográfica do rio Munim, está situado entre as coordenadas geográficas: $3^{\circ} 40^{\prime}-4^{\circ} 00^{\prime} \mathrm{S}$ e $42^{\circ} 56^{\prime}-43^{\circ}$ 52' W. Após percorrer 270,92 km, deságua no rio Munim, no município de Nina Rodrigues (Figura 1).

Toda a bacia hidrográfica do Rio Preto situa-se no domínio do Cerrado sendo este o segundo maior bioma da América do Sul, ocupando uma área de $2.036 .448 \mathrm{~km}^{2}$, cerca de 22\% do território nacional (MMA, 2018).

A bacia abrange quatorze municípios maranhenses, sendo dez deles pertencentes à Mesorregião Leste Maranhense, a saber: Anapurus $\left(561.23 \mathrm{~km}^{2}\right)^{1}$, Chapadinha (482.59 $\mathrm{km}^{2}$ ), Mata Roma $\left(548.32 \mathrm{~km}^{2}\right)$, Buriti $\left(540.19 \mathrm{~km}^{2}\right)$, Brejo $\left(232.17 \mathrm{~km}^{2}\right)$, Urbano Santos (994.75 km²), Belágua (471.82 km²), São Benedito do Rio Preto $\left(848.23 \mathrm{~km}^{2}\right)$, Milagres do Maranhão (33.98 km²), Santa Quitéria do Maranhão $\left(9.83 \mathrm{~km}^{2}\right)$ - com exceção deste último, os demais pertencem à Microrregião de Chapadinha. Já os quatro municípios restantes: Nina Rodrigues $\left(210.27 \mathrm{~km}^{2}\right)$, Presidente Vargas $\left(69.24 \mathrm{~km}^{2}\right)$, Cachoeira Grande $\left(7.27 \mathrm{~km}^{2}\right)$ e Morros $\left(225.34 \mathrm{~km}^{2}\right)$ pertencem à Mesorregião Norte Maranhense.

\footnotetext{
${ }^{1}$ Corresponde à área em $\mathrm{km}^{2}$ do município que é banhado ou abrangido pela bacia do Rio Preto - MA.
} 
Figura 1: Mapa de localização da bacia hidrográfica do Rio Preto - MA

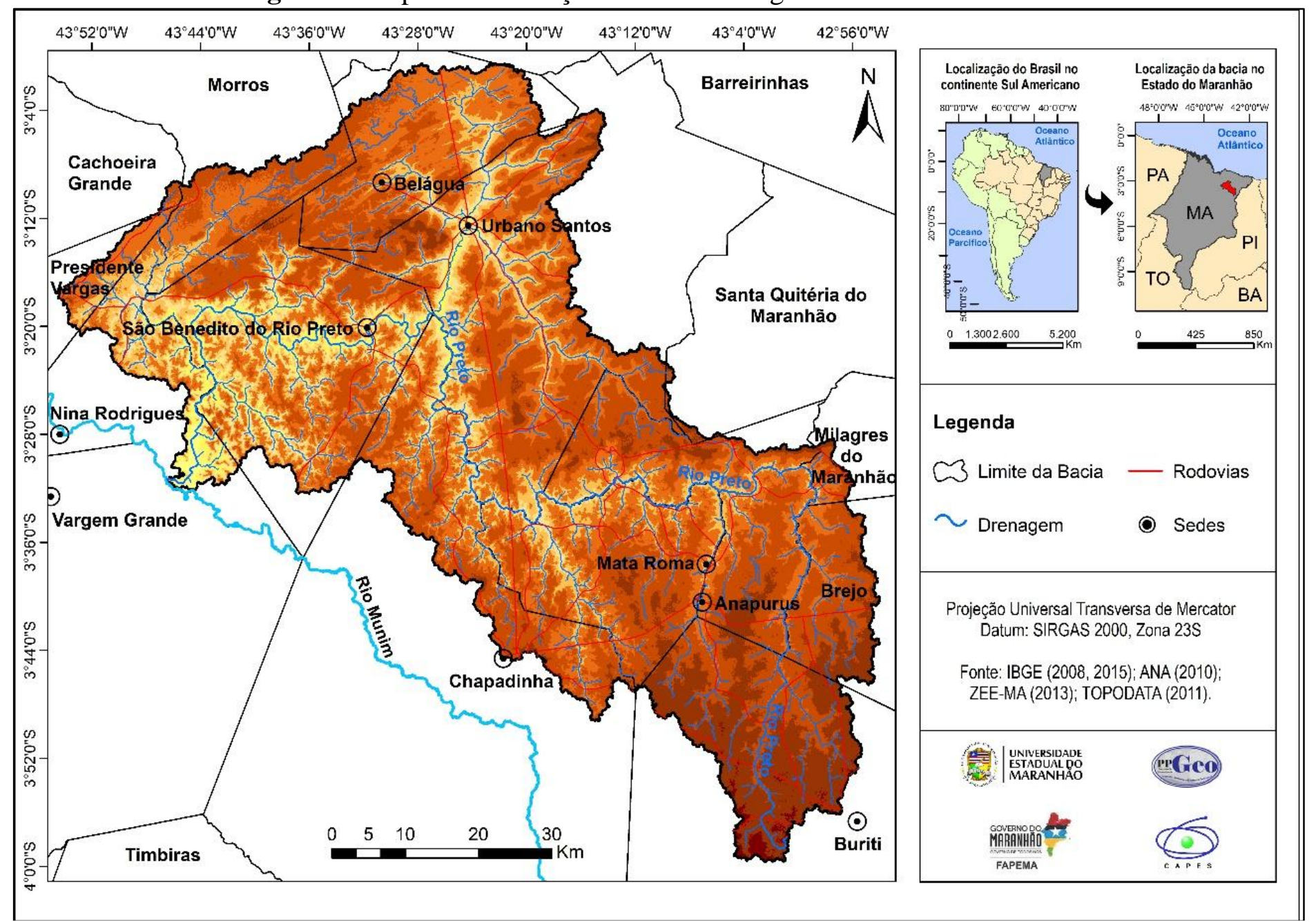

Org.: Soares et al. (2019). 
No campo maranhense existem atores sociais com motivos e interesses específicos em relação ao uso da terra, de um lado tem-se o camponês com seu modo de vida baseado na agricultura de subsistência e do outro o empresariado voltado para o agronegócio, especificamente para o cultivo de monoculturas (soja, eucalipto). Esse último ator social tem causado um impacto significativo na dinâmica do uso da terra na bacia (RODRIGUES; TERRA, 2018).

Face ao exposto, faz-se necessário definir de antemão os termos campesinato e camponês. Neste sentido, o campesinato neste trabalho é entendido de acordo com a concepção de Costa e Carvalho (2012, p.115), que o definem como:

\begin{abstract}
O conjunto de famílias camponesas existentes em um território. As famílias camponesas existem em territórios, isto é, no contexto de relações sociais que se expressam em regras de uso (instituições) das disponibilidades naturais (biomas e ecossistemas) e culturais (capacidades difusas internalizadas nas pessoas e aparatos infraestruturais tangíveis e intangíveis) de um dado espaço geográfico politicamente delimitado.
\end{abstract}

A bacia hidrográfica do Rio Preto banha, predominante, a Mesorregião Leste Maranhense, de acordo com Nascimento (2010, p.12), é uma região onde há o predomínio da agricultura camponesa e extrativista com destaque para as culturas temporárias de arroz, milho, feijão e mandioca e com predominância do extrativismo de babaçu, carnaúba, pequi e bacuri, sendo o primeiro, o mais significativo na economia regional e também na economia camponesa.

A Figura 2 mostra a casa de farinha e a última etapa do processo de fazer farinha d'água usada pelas famílias camponesas maranhenses. $\mathrm{Na}$ área rural dos municípios da microrregião de Chapadinha essas instalações são comuns nos povoados. 
Figura 2: Casa de farinha e forno localizado no povoado Bacabal no município de Chapadinha - MA

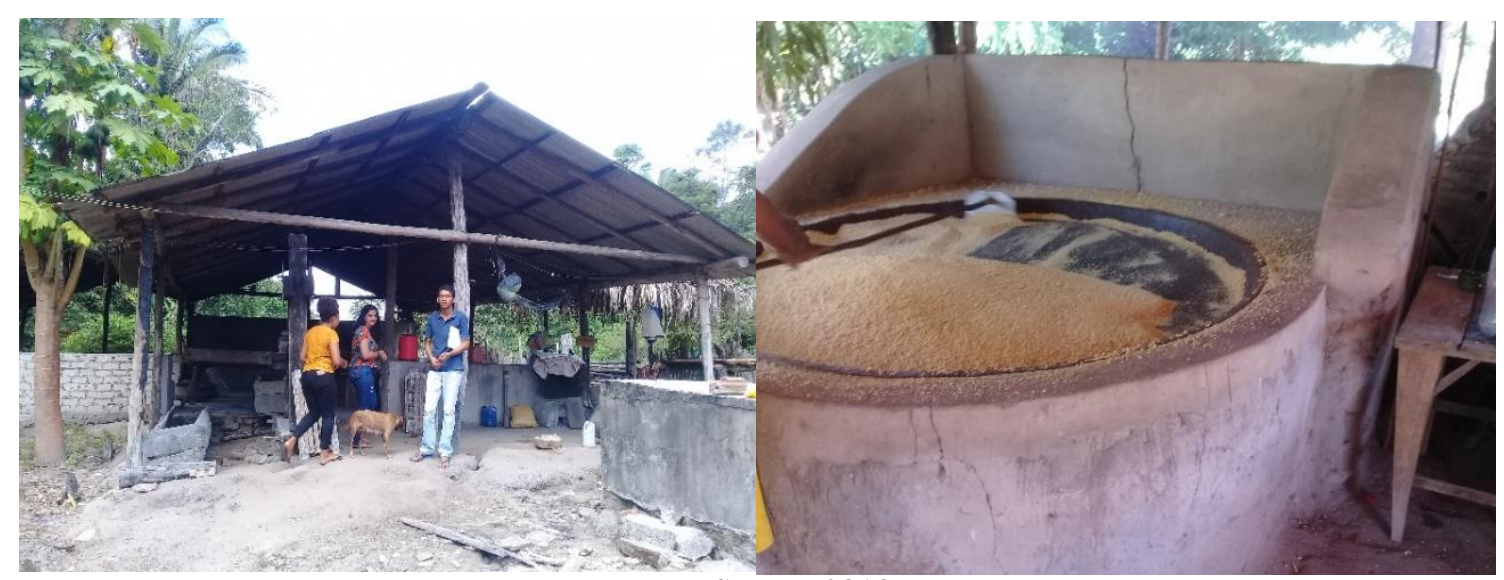

Fonte: Santos, 2018.

Ainda em relação aos camponeses, em específico os que vivem nos municípios do Leste Maranhense, sua economia baseada na produção de alimentos se caracteriza pela apropriação e manejo de diferentes recursos naturais, sobretudo de dois distintos ambientes - as áreas chamadas regionalmente de baixo que, conforme Paula Andrade (2008), são áreas bastante úmidas próximas a rios e riachos e aquelas de chapadas, classificadas como áreas constituídas de terrenos planos, com presença de árvores de porte baixo, esparsas e de uma espécie de capim denominado agreste. Estes terrenos são apropriados para a caça, coleta de fruto e plantas medicinais, assim como para a criação de animais. Articulando a apropriação e o manejo desses dois tipos de ambiente, as famílias desenvolvem diferentes atividades econômicas importantes para a manutenção de seu grupo familiar, atividades como: a agricultura voltada tanto para o consumo da sua família, como para a comercialização (BOTELHO; ALMEIDA; FERREIRA, 2012).

\section{Territorialização das agroindústrias na Mesorregião Leste Maranhense}

A região Leste Maranhense desde o início dos anos de 1980 tornou-se uma nova fronteira agrícola para onde se dirigiam diversos projetos de expansão do agronegócio, a exemplo do eucalipto; tendo como principal objetivo, adquirir matéria-prima para a produção de carvão vegetal a serem utilizadas na fabricação de ferro-gusa. Já a soja chegou à região no final da década de 1990 e deu continuidade à implantação desses outros monocultivos (NASCIMENTO, 2010). A Figura 3 apresenta duas agroindústrias dentre várias outras localizadas na área de estudo. 
Figura 3: Agroindústrias presentes na zona rural do município de Anapurus - MA

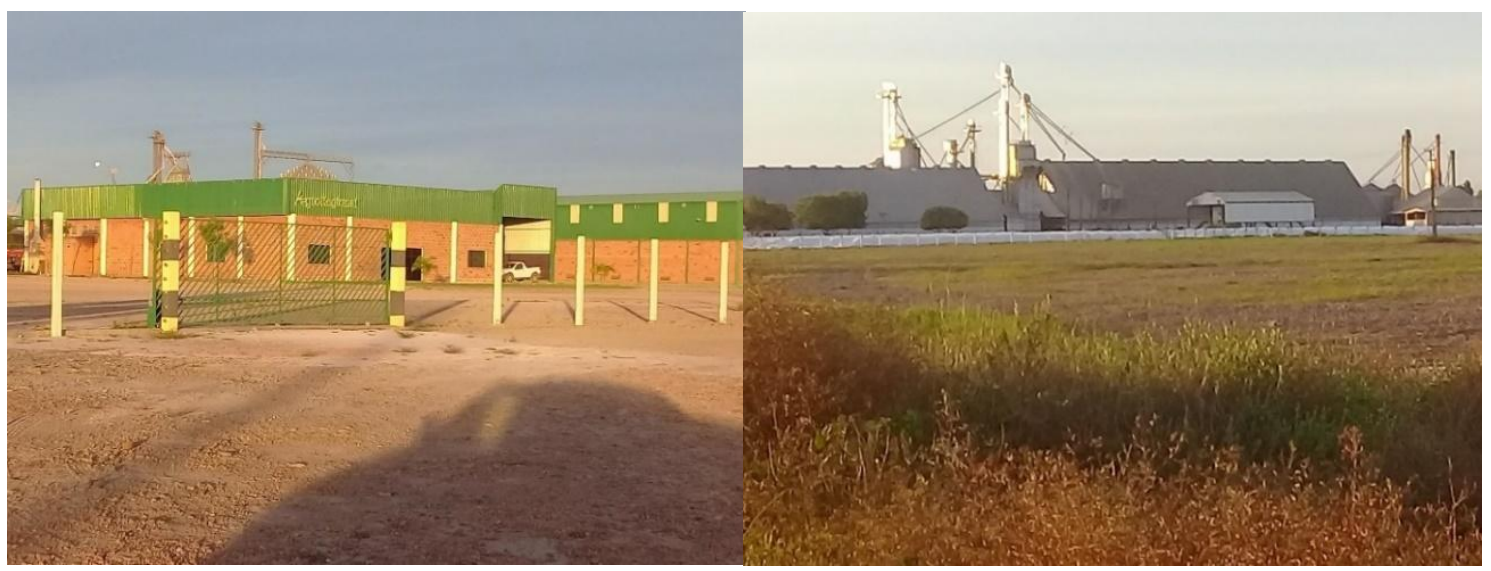

Fonte: Santos, 2018.

Ainda em relação a esses monocultivos identificados na área de estudo, Gaspar; Rego; Andrade (2008, p.3-4) afirmam que:

\begin{abstract}
A partir da década de 1980, instalaram-se no Leste Maranhense, empresas nacionais e estrangeiras voltadas à produção de carvão vegetal e à plantação de eucalipto. A produção de carvão vegetal proveniente da queima de algumas espécies de madeiras nativas destinava-se, dentre outras atividades, a alimentar guseiras da siderúrgica Maranhão Gusa S/A-MARGUSA. Já o plantio de eucalipto, em áreas de municípios maranhenses do Leste Maranhense, visava a produção de celulose, tendo o Grupo Industrial João Santos de Pernambuco e a Suzano Celulose de São Paulo como principais empresas.
\end{abstract}

Neste contexto, o avanço do agronegócio frente ao campesinato do Leste Maranhense foi consolidado pelas empresas MARGUSA, MARFLORA e Suzano Papel e Celulose. Segundo Paula Andrade (1995), a MARGUSA (Siderúrgica Maranhão Gusa S/A) foi fundada em 1985 por empresários maranhenses com incentivos da SUDENE (Superintendência de Desenvolvimento do Nordeste) e vendida, posteriormente ao grupo japonês Yanmar do Brasil S/A. No ano de 2003, a MARGUSA foi comprada pelo grupo siderúrgico GERDAU. Já a MARFLORA era o braço florestal da MARGUSA (RIBEIRO JÚNIOR; OLIVEIRA; COSTA, 2014, p.16).

A empresa GERDAU usa o eucalipto como matéria prima para a produção do carvão vegetal para alimentar as guseiras (empresas que transformam o minério em ferrogusa, matéria-prima para a produção de aço), já a Suzano Papel e Celulose utiliza o eucalipto para produção de celulose, matéria prima que é usada na fabricação de guardanapos, papel higiênico, papéis para imprimir e escrever, entre outros itens.

Vale salientar que o investimento de uma determinada empresa em um dado território, sempre tem por base um estudo prévio para que o investimento seja realizado 
de forma a garantir lucros. Neste sentido, Ribeiro Júnior, Oliveira e Costa (2014, p.20) elucidam que:

\begin{abstract}
O interesse da Suzano no Leste Maranhense deve-se a vários fatores dos quais podem ser destacados: a proximidade da infraestrutura de escoamento (rodovias, como a BR 135; proximidade para com o Porto do Itaqui, em São Luís), bem como a maior parte de suas terras (do Leste Maranhense) serem classificadas como de boa aptidão para a silvicultura.
\end{abstract}

No que diz respeito à soja, especificamente, na microrregião de Chapadinha, sua chegada ocorre por meio do estabelecimento de agricultores provenientes de estados da região Sul e Centro-Oeste, que encontram na região uma boa possibilidade de cultivo da soja especialmente pela maior facilidade de escoamento da produção, representada pela proximidade da localização da microrregião com o porto do Itaqui e do Terminal de Grãos da Companhia Vale, além da facilidade de aquisição de extensas áreas de terras férteis ocasionado tanto pelo baixo custo a que essas terras eram vendidas pelos proprietários originais, como pela falta de uma regularização fundiária na região (SANTOS, 2016).

Ressalta-se que os "agricultores provenientes do sul do Brasil conhecidos por gaúchos, denominação que envolve indistintamente gentílicos do Rio Grande do Sul, São Paulo, Paraná, Santa Catarina dentre outros" (BOTELHO; DINIZ, 2012, p.2) são os atores sociais que estão presentes nos municípios que formam a microrregião de Chapadinha e que na área de estudo cultivam extensas áreas sojicultoras para a exportação (ALMEIDA et al., 2019).

De acordo com Presoti (2008, p.46), a microrregião de Chapadinha corresponde a $78 \%$ da produção no Leste Maranhense e, dentre os 9 municípios que formam a microrregião, 4 municípios destacam-se, no tocante à produção de soja: Anapurus (43,79 $\mathrm{km}^{2}$ ), Brejo $\left(79,2 \mathrm{~km}^{2}\right)$, Buriti $\left(73,83 \mathrm{~km}^{2}\right)$, Mata Roma $\left(26,7 \mathrm{~km}^{2}\right)$. Tais municípios são responsáveis por $91 \%$ da área plantada na microrregião e correspondem a $74 \%$ de todo Leste Maranhense.

O aumento nos índices de produção da monocultura sojicultora no Maranhão é decorrente dos incentivos dados pelo Estado, como o convênio estabelecido entre o governo brasileiro e a Agência de Cooperação Internacional do Japão (JICA) denominado de Programa do Corredor de Exportação Norte, Programa de Cooperação Nipo-Brasileiro para o Desenvolvimento dos Cerrados (PRODECER III), além de outros convênios celebrados pelo Estado. 
O Corredor de Exportação Norte favorece a logística de transporte e escoamento da produção de grãos, principalmente de soja para o mercado internacional (Europa, Estados Unidos). Este corredor abrange os estados do Sudeste do Piauí, Sul do Maranhão e Norte e Sudeste do Tocantins. Neste contexto, Pereira; Rocha; Bonacim (2008, p.162) afirmam que:

\begin{abstract}
O corredor norte de exportação possui vários itens necessários para uma melhor logística de recebimento de insumos e distribuição de grãos produzidos na região: (i) potência de produção - o sul do Maranhão e Piauí, norte do Tocantins, têm 4.925.000 ha de cerrado, ideal para agricultura e próprio para o cultivo de soja, milho e outros cereais; (ii) encontra-se, também na região, uma moderna ferrovia administrada pela Vale do Rio Doce, que liga Carajás ao Porto de Itaquí, em São Luís/MA, ligando à ferrovia Norte Sul, com trecho construído até a cidade Porto Franco, onde existe um terminal intermodal (local onde os caminhões descarregam a carga para a ferrovia), ligando a ferrovia com a rodovia Belém - Brasília e hidrovia pelo Rio Tocantins e Araguaia.
\end{abstract}

Ainda conforme os autores, a soja produzida na região é transportada pela ferrovia, vai até São Luís, e de lá segue por navios até o mercado consumidor, com a vantagem de São Luís estar $4000 \mathrm{~km}$ mais perto de Roterdã, na Europa, do que o porto de Paranaguá/PR, porto de maior movimentação agrícola do país.

Já o PRODECER foi pensado e concebido a partir de 1974 entre os governos do Brasil e do Japão, foi um dos que mais contribuiu para mudanças na paisagem e no perfil econômico e social, transformando espaços dos cerrados da Região Centro-Oeste e nos cerrados dos Estados de Minas Gerais, Mato Grosso, Mato Grosso do Sul, Bahia, Tocantins e Maranhão no principal polo de crescimento da agricultura brasileira dos últimos 40 anos (SANTOS, 2016).

No que diz respeito aos programas de cooperação entre países para o setor agrícola da economia, o PRODECER é considerado o mais importante e o de mais longa duração firmado no Brasil. "A partir de 1979 o Programa foi implantado em três fases: PRODECER I Piloto, de 1979 a 1983; O PRODECER II Piloto e PRODECER de Expansão, de 1985 a 1993; e O PRODECER III Piloto, iniciado em 1995 e encerrado em 2001”. (SANTOS, 2016, p.395).

O PROCEDER III teve suas ações executadas nos municípios de Balsas (sul do Estado do Maranhão) e Pedro Afonso (Estado de Tocantins). "Essa nova etapa representou a continuidade de um trabalho destinado a incorporar novas áreas de cerrados 
no Brasil à atividade agropecuária moderna fora do eixo e proximidade da região Centro-

Oeste do país" (SANTOS, 2016, p.403).

Ainda conforme o autor mencionado:

O PRODECER representou uma nova forma de intervenção no campo, com o apoio das estruturas e instituições de Estado no direcionamento da ocupação e criação de uma nova fronteira agrícola no país. O Estado ficou imbuído de constituir instituições, traçar e executar um conjunto de ações, programas, projetos e definições de natureza política que exercessem o papel de criar bases para a acumulação capitalista nos setores agrícolas nacionais (SANTOS, 2016, p.404).

Conforme Nascimento (2010, p.11), a produção de soja contou com recursos financeiros estatais e privados, a exemplo da agência de cooperação internacional do Japão que deu origem ao Programa de Desenvolvimento do Cerrado III (PRODECER), dando continuidade a uma série desse programa já iniciado em outras áreas do cerrado brasileiro com o objetivo de expandir a produção de grãos para o mercado internacional.

O Estado tem um papel relevante no processo de implantação destas empresas ao conceder incentivo viabilizando sua instalação nas áreas urbanas ou rurais uma vez que o interesse destes empreendimentos coadunam com os dos governantes do País e consequentemente do governo estadual, é desta forma, em busca do denominado desenvolvimento econômico regional o empresariado ganha forças para colocarem em ação seus projetos no Maranhão em especial na Mesorregião Leste Maranhense. É necessário salientar que o estado fomenta a expansão do agronegócio de diversas formas tais como: incentivos fiscais, juros subsidiados, credito rural entre outros. Esse incentivo ocorreu no caso da execução do programa PRODECER.

\section{Causas e consequências dos conflitos territoriais na bacia do Rio Preto-MA}

O Maranhão tem sido palco, assim como vários outros estados da federação, da proliferação de conflitos ambientais oriundos majoritariamente da exploração ambiental exacerbada do agronegócio e da expropriação e expulsão dos camponeses de suas terras pela ação do avanço dos latifúndios que se dedicam ao agronegócio que tem como principal objetivo o aumento do lucro através da produção de commodities, contribuindo assim para a reprodução ampliada do capital (FERNANDES, 2000). A emergência e o crescimento da produção de soja no Maranhão decorrem da necessidade do capital em 
incorporar novas terras à agricultura, a fim de assegurar sua reprodução em detrimento da produção de subsistência camponesa.

$\mathrm{Na}$ Mesorregião Leste Maranhense que é preponderantemente banhada pela bacia do Rio Preto tal pensamento se apresenta reproduzindo uma característica que predomina majoritariamente no País, resultando em muitas ameaças e conflitos territoriais motivados na luta pela terra por parte dos camponeses que resistem contra as ações do agronegócio que visa se apropriar a qualquer custo, das porções territoriais camponesas. Algumas empresas têm se instalado na Mesorregião Leste Maranhense na área do cerrado para desenvolvimento de seus projetos exportadores, fortalecendo ainda mais o agronegócio no Maranhão e em consequência a reprodução ampliada do capital.

Evidencia-se que a expansão da fronteira agrícola no contexto da monocultura do eucalipto, como mencionado, desempenhou a partir de 1980 um papel decisivo na transformação do espaço, se antes dessa década havia áreas com vegetação nativa, típica do Cerrado, atualmente ela sede lugar a monocultivo baseado no agronegócio, onde há um alto investimento em capital, tecnologia, bactericidas, adubos sintéticos e ainda financiamentos por agências de fomento, ou seja, tudo que possa ser essencial para expansão do capital (OLIVEIRA, 2019).

O cultivo do eucalipto com a finalidade de atender a demanda do agronegócio tem gerado um conflito histórico na área de estudo envolvendo de um lado o camponês, com seu modo de vida, que tem no bioma Cerrado uma fonte de obtenção de alimentos, de matéria prima para produção de utensílios, etc. e do outro; o agronegócio que tem encontrado nesse bioma uma possibilidade de investimento, expansão e reprodução do capital. Neste contexto, há um conflito pela posse da terra na área de estudo envolvendo esses atores sociais (SODRÉ et al., 2019).

Assim, como o eucalipto há em relação à soja, conflitos pela posse da terra. Esses conflitos ocorrem entre pessoas com maior poder aquisitivo, dentre elas as empresas ligadas ao agronegócio, seja ela de produção de grãos, carvão ou madeira, fazendeiros, e pessoas de baixo poder aquisitivo, ou seja, as comunidades tradicionais (camponeses, assentados, quebradeiras de coco babaçu, etc.). Neste contexto, a Figura 4 mostra os monocultivos e a Figura 5 expõe a quantidade de conflitos ocorridos nos municípios banhados pela bacia. 
Figura 4: Plantio de eucalipto na zona rural do município de Buriti e de soja em Anapurus - MA

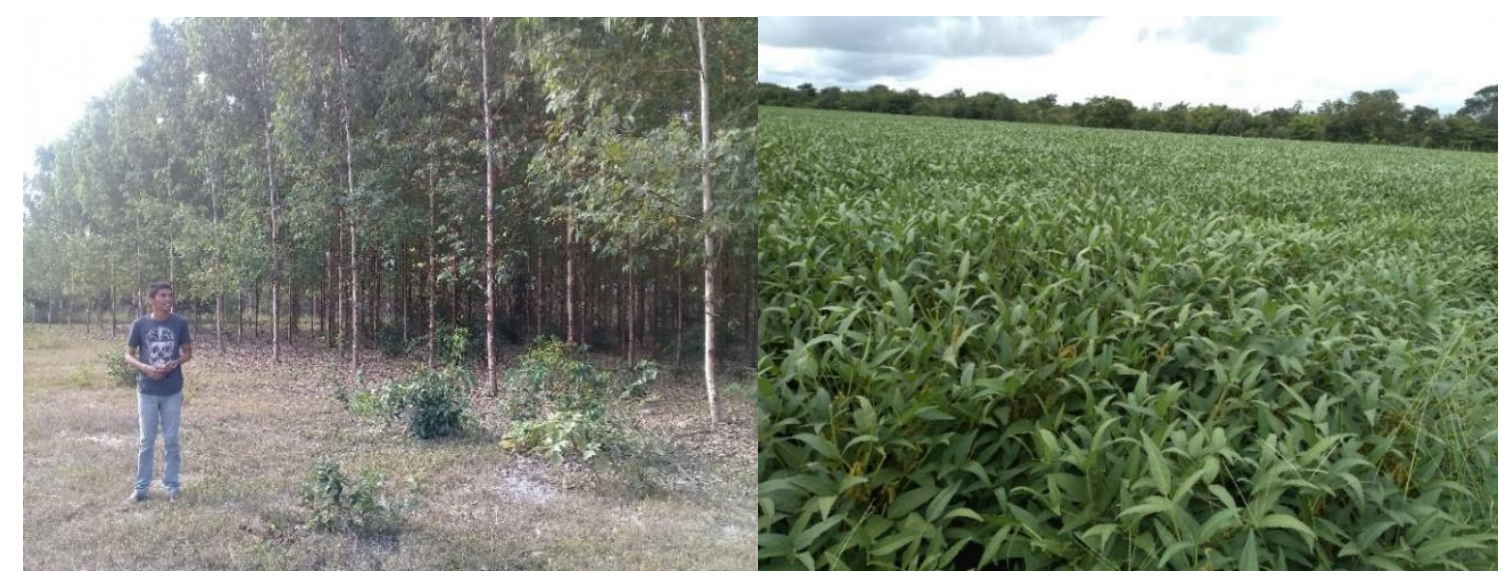

Fonte: Santos, 2019.

Entendemos os conflitos por terra da mesma forma que a CPT (2016, p.16), que define como sendo as ações de resistência e enfrentamento pela posse, uso e propriedade da terra e pelo acesso aos recursos naturais, tais como: seringais, babaçuais ou castanhais, dentre outros (que garantam o direito ao extrativismo), quando envolvem posseiros, assentados, quilombolas, indígenas, pequenos arrendatários, camponeses, ocupantes, sem-terra, seringueiros, camponeses de fundo de pasto, quebradeiras de coco babaçu, castanheiros, faxinalenses, dentre outras. As ocupações e os acampamentos são também classificados na categoria de conflitos por terra.

Entre 2000 a 2018, 316 conflitos foram registrados na área de estudo, somandose a quantidade de ocorrência de conflitos em todos os municípios abrangidos pela bacia do Rio Preto. Destacam-se os municípios de Urbano Santos com um total de 68 conflitos, Santa Quitéria do Maranhão com 51 casos, Belágua com 50 registros e Chapadinha totalizando 43 ocorrências.

Tais conflitos, infelizmente, têm gerado um quadro desolador de mortes no campo. Esses assassinatos são motivados por conflitos por posses de terra e também ocorre na região a chamada grilagem de terras (PAULA ANDRADE, 1995). A grilagem é o sistema ou organização ou procedimento dos grileiros, estes últimos que procuram apossar-se de terras alheias mediante falsas escrituras de propriedades (MOTTA, 2005). 
Figura 5: Mapa de conflitos por terra da bacia do Rio Preto - MA (2000-2018)

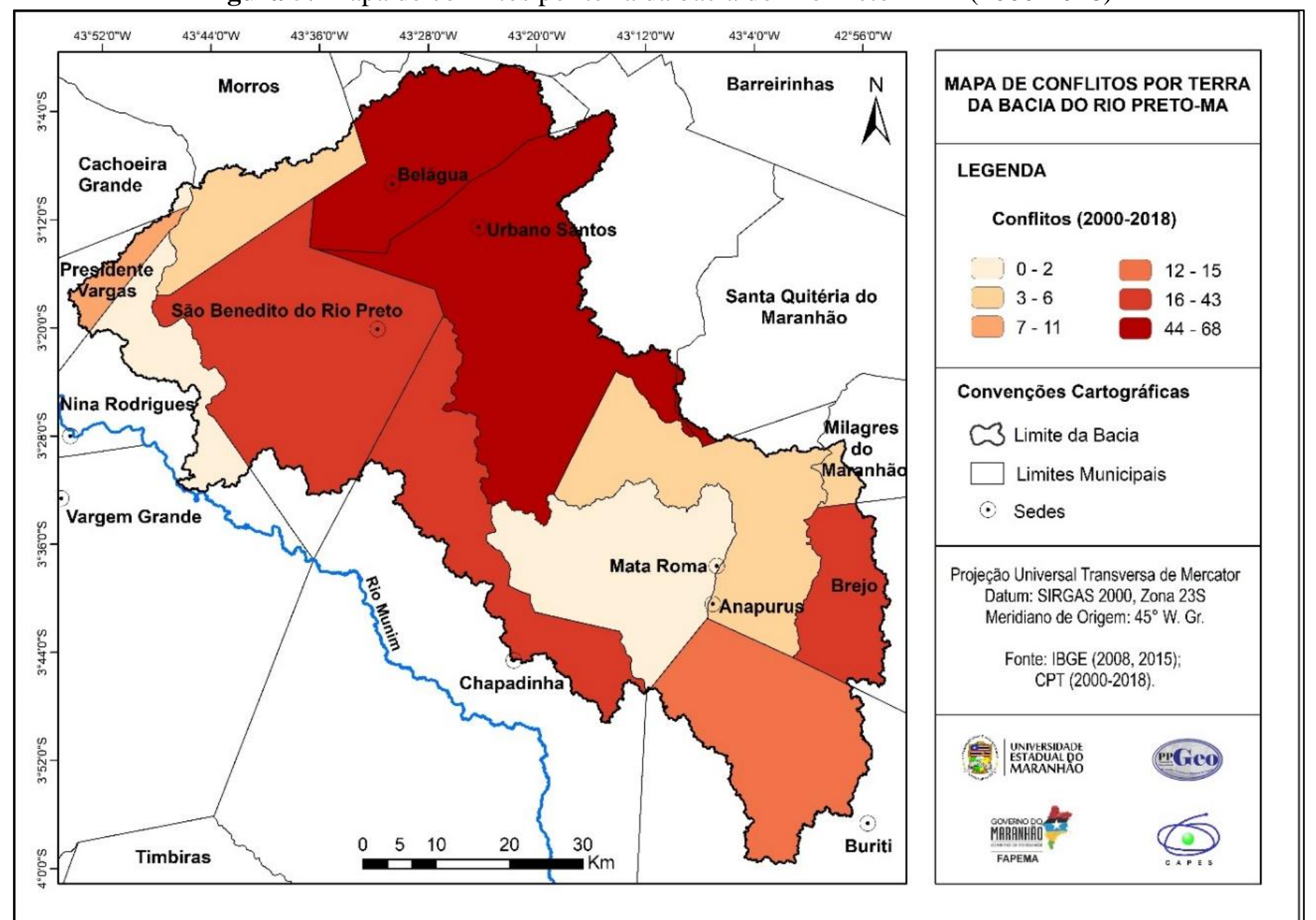

Org.: Soares et al., 2019. 
As empresas do agronegócio que exploram o campo se apropriam da terra, por vezes de maneira ilegítima e fraudulenta, para subjugá-la à exploração produtiva e comercial. A sojicultora e a silvicultura nessa mesorregião tem sido os principais investimentos capitalista no campo que além de produzir "profundas mudanças nas relações de trabalho" (LIMA; LOCATEL; SILVA, 2012), gera sérias degradações ambientais no cerrado e a expropriação de comunidades locais que têm no bioma cerrado a fonte para o extrativismo vegetal e da caça para obtenção do sustento de suas famílias.

$\mathrm{Na}$ área de pesquisa, depois da significativa destruição do cerrado nativo com o emprego do uso de correntões ${ }^{2}$, para a geração de energia de biomassa visando o abastecimento de usinas siderúrgicas e posteriormente abrem espaço para o plantio do eucalipto. Estes projetos de desenvolvimento têm sido operados por grupos econômicos que investem na produção madeireira, como no caso da Suzano Papel e Celulose que se instalou nos municípios de Anapurus, Urbano Santos, Milagres do Maranhão, Santa Quitéria do Maranhão. Assim o avanço do agronegócio tem ocasionado mudanças socioeconômicas e ambientais em ritmos cada vez mais velozes, tal como tem sido observado nesses municípios.

No contexto dos problemas ambientais relacionados ao eucalipto, Ribeiro Júnior; Oliveira; Costa (2014) a partir de trabalhos de campo e acompanhamento dos conflitos, nos municípios de Santa Quitéria do Maranhão e Urbano Santos delinearam impactos ambientais decorrentes da ação da Suzano Papel e Celulose.

Os autores afirmam que a Suzano tem causado uma gama de impactos ambientais (como captação de água de rios, lagos e lagoas, que prejudica o abastecimento nos povoados); desmatado/queimado as chapadas com vistas ao plantio de eucalipto; destruindo formas de vida animal e vegetal através dos correntões; danificado, corpos hídricos e o solo com a utilização de venenos, principalmente herbicidas. Eles ainda relatam que os camponeses alegam que a Suzano matou muitos animais, caças, destruiu muitos pés de bacuri, pequi, via correntão.

A produção de carvão vegetal foi encontrada no município de Buriti no povoado Baixinha, esses fornos para a produção de carvão utilizam madeiras nativas do cerrado,

\footnotetext{
${ }^{2}$ Grossas correntes, de várias toneladas, amarradas a tratores de esteira e que vão arrancando árvores e toda a vegetação presente nas áreas chamadas chapadas, de modo a preparar o terreno para o plantio da soja ou do eucalipto (PAULA ANDRADE, 2011).
} 
essa produção não tem licença do órgão competente para desenvolver a atividade de produção de carvão. A Figura 6 (A) apresenta uma ampla área de solo exposto para cultivo de soja no município de Mata Roma, (B) mostra a área de extração de minério em Chapadinha, (C) lixão a céu aberto, (D) desmatamento em Área de Preservação Permanente, $(\mathrm{E})$ roça de toco, $(\mathrm{F})$ contaminação de bacurizeiros por agrotóxicos, ambos no mesmo município, (G) área com presença de fornos para produção de carvão vegetal no município de Buriti.

Diante do exposto constata-se que o uso da terra na área-objeto causou e ainda tem causado diversos problemas ambientais como as queimadas, desmatamento, contaminação por agrotóxicos, a destruição de formas animais e vegetais, etc. Todas essas ações antrópicas têm ocasionado um impacto não apenas a bacia, como também os outros componentes do ambiente, sendo alguns desses componentes ambientais imanentes a bacia, a saber: a vegetação nativa, solo, fauna, microrganismos, etc. Neste contexto, os atores sociais presentes na área de pesquisa têm influenciado significativamente na alteração da dinâmica natural da bacia do Rio Preto.

Pode-se afirmar que a partir das décadas de 80 e 90 iniciou-se na área de pesquisa o surgimento de múltiplos territórios, dentre os quais: o território do eucalipto e o da soja. Esses novos territórios se contrapõem ao território do campesinato. São territórios que seguem uma dinâmica própria e que se opõem devido as lógicas distintas de ocupação do território.

Essas implicações envolvendo o camponês e o empresariado são corroboradas no entendimento das dimensões horizontais e verticais apresentadas por Ribeiro (2005, p.147):

O território é a arena da oposição entre mercado - que singulariza - com as técnicas da produção, a organização da produção, a "geografia da produção" e a sociedade civil - que generaliza - e desse modo envolve, sem distinção, todas as pessoas. Com a presente democracia de mercado, o território é suporte de redes que transportam as verticalidades, isto é, regras e normas egoísticas e utilitárias (do ponto de vista dos atores hegemônicos), enquanto as horizontalidades levam em conta a totalidade dos atores e das ações. 
Figura 6: Carta-imagem de problemas ambientais da bacia do Rio Preto-MA

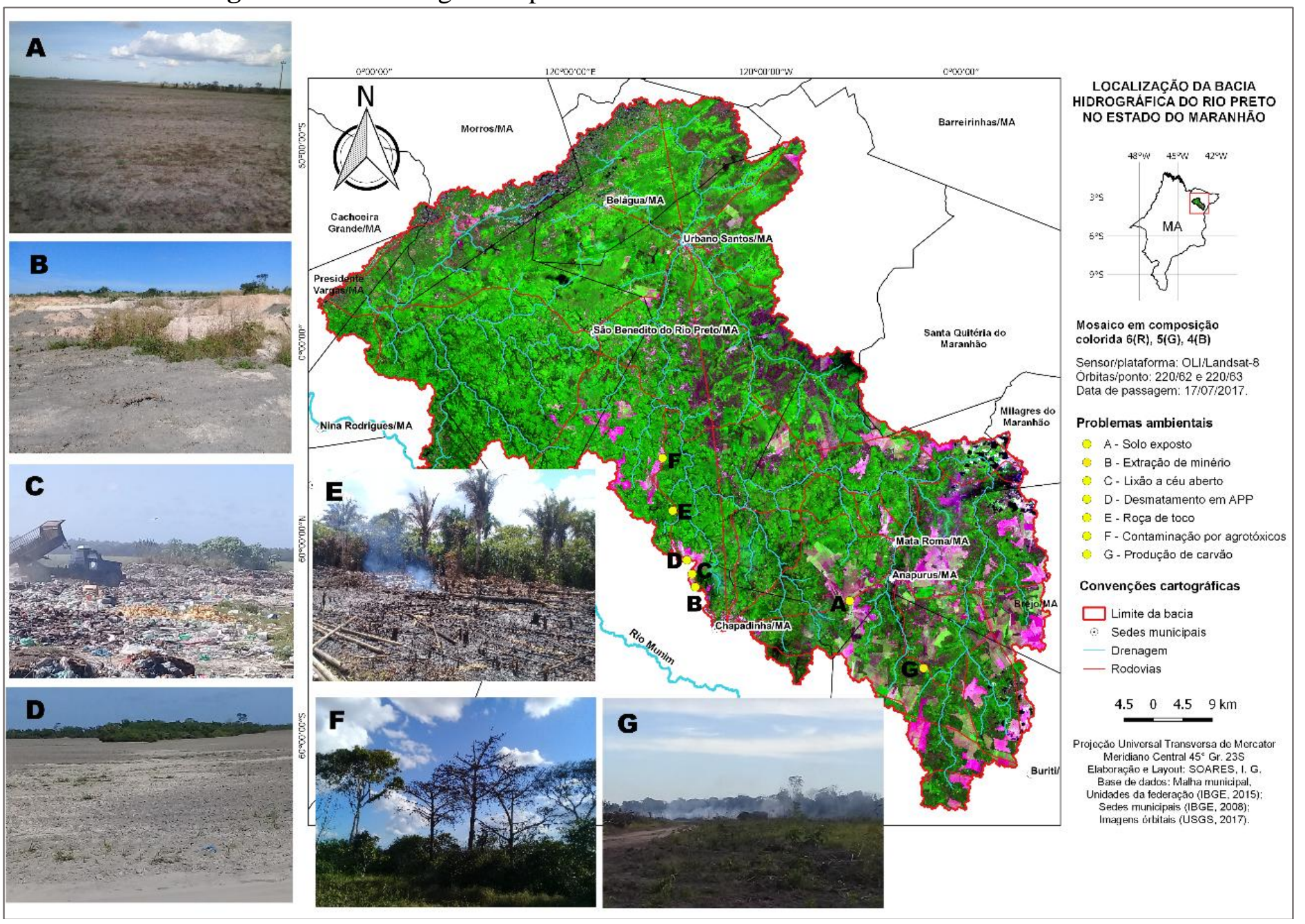

Org.: Soares et al., 2018. 
As verticalidades na bacia estão representadas nas atividades do agronegócio que criam desordem nos territórios onde se instalaram, porque a ordem que criam é em seu próprio benefício, tal implicação é notada no caso da soja que tem por finalidade a exportação, principalmente, para a China. É o que Santos (1996) chama de modernização alienada, pois são fatores e processos que estão distantes da vida da população local, ou seja, da vida campesina. Os camponeses, por sua vez, estão representados na dimensão horizontal que corresponde às atividades e ações que possibilitam a estruturação da vida social. “As horizontalidades são os domínios da contiguidade, daqueles lugares vizinhos reunidos por uma continuidade territorial”. (SANTOS, 2005, p.256).

Pode-se falar neste contexto que no mesmo território existem lugares contíguos e em redes, sendo que este último erigiu e reforçou as verticalidades. Esta noção de redes se relaciona ao território daquelas formas e normas ao serviço de alguns que se contrapõe ao chamado espaço banal, ou seja, o território de todos. "Contrapõem-se, assim, o território todo e algumas de suas partes, ou pontos, isto é, as redes. Mas, quem produz, quem comanda, quem disciplina, quem normaliza, quem impõe uma racionalidade às redes é o Mundo". (SANTOS, 2005, p.259).

Ainda conforme Santos (2005, p.259),

Quando se fala em Mundo, está se falando, sobretudo, em Mercado que hoje, ao contrário de ontem, atravessa tudo, inclusive a consciência das pessoas. Mercado das coisas, inclusive a natureza; mercado das ideais, inclusive a ciência e a informação; mercado político. Justamente, a versão política dessa globalização perversa é a democracia de mercado.

De forma geral, o avanço das atividades industrializadas no campo brasileiro com repercussões no Maranhão, ocorrem de modo perene e em ritmo crescente, e isso se deve particularmente pelas práticas adotadas pelas diferentes escalas de governo, sob a égide de um discurso da pretensa busca de uma melhoria econômica através da industrialização do país e, como também, pela força exercida de forma estratégica pelos empresários da agroindústria, em detrimento de um planejamento que contemplasse também de modo qualitativo as comunidades camponesas locais.

\section{Resistência camponesa}


Em contrapartida a todas as investidas perversas da agricultura capitalista nos municípios que são abrangidos pela bacia do Rio Preto, principalmente, os da Mesorregião Leste Maranhense, os camponeses afetados pelo avanço da soja, do eucalipto e da produção de carvão, têm se organizado de diferentes modos para resistirem à grande pressão exercida pelas práticas destas atividades. Em razão da grande disparidade de forças entre os camponeses e os grandes empresários do agronegócio, surgiu recentemente, movimentos de mobilização, coordenados por entidades como associações de moradores e sindicatos rurais em articulação com organizações não governamentais - ONGs e integrantes da Igreja Católica, com o objetivo de defender o bioma do cerrado e as condições de vida dos camponeses frente à expansão do agronegócio (GASPAR; REGO; PAULA ANDRADE, 2008; NASCIMENTO, 2010).

Nesse sentido, iniciativas como o Banco de Dados da Luta pela Terra (DATALUTA), que subsidia o Centro de Documentação do MST, criado por meio do convênio entre a Universidade Estadual Paulista e o Movimento dos Trabalhadores Rurais Sem Terra (FERNANDES, 2012), permitem o desafio de mapeamento e análise dos sinais de resistência dos camponeses em escala nacional. Com base nesses dados, fizemos um recorte para nossa área de estudo (Tabela 1 e Figura 7). A pressão dos camponeses reflete em conquistas territoriais reconhecidas pelo estado. A resistência camponesa pode ser considerada menos violenta, quando da intervenção de algum órgão do governo, de entidades com grande reconhecimento, da igreja católica, embora muitas vezes possa ocorrer episódios com o uso da violência de ambas as partes, porém geralmente os mais letais são causados pela reação dos latifundiários que estrategicamente busca eliminar as lideranças dos camponeses (FERNANDES, 2000).

A forma de não se submeter ao capital agrário, também é uma maneira de resistência, existindo indivíduos que não cedem suas terras para a ampliação territorial da produção da soja e eucalipto, assim como se submeter ao modo de produção exploratório, pois os camponeses usufruem dos elementos naturais como forma de produzir e reproduzir materialmente o conteúdo de sua existência e sociabilidade baseada pelo trabalho familiar (VAN DER PLOEG, 2009).

Tabela 1: Bacia hidrográfica do Rio Preto - Área de assentamento desapropriado e reconhecido por município 


\begin{tabular}{lccc}
\hline \multicolumn{1}{c}{ Municípios } & $\begin{array}{c}\text { Área desapropriada (em } \\
\text { hectares) }\end{array}$ & $\begin{array}{c}\text { Área reconhecida } \\
\text { (em hectares) }\end{array}$ & $\begin{array}{c}\text { Área total (em } \\
\text { hectares) }\end{array}$ \\
\hline Anapurus & $1.219,00$ & 00,00 & $1.219,00$ \\
Belágua & $7.827,54$ & 210,00 & $8.037,54$ \\
Brejo & $5.833,97$ & 927,78 & $6.761,75$ \\
Buriti & $3.821,74$ & $2.723,00$ & $6.544,74$ \\
Cachoeira Grande & $21.744,59$ & $4.279,46$ & $26.024,05$ \\
Chapadinha & $21.689,13$ & $11.971,24$ & $33.660,37$ \\
Mata Roma & 00,00 & 00,00 & 00,00 \\
Milagres do Maranhão & $1.295,46$ & 00,00 & $1.295,46$ \\
Morros & $27.750,00$ & $49.254,42$ & $77.004,42$ \\
Nina Rodrigues & $21.042,93$ & 456,23 & $21.499,16$ \\
Presidente Vargas & $5.752,34$ & 142,53 & $5.894,87$ \\
Santa Quitéria do Maranhão & 00,00 & $4.408,18$ & $4.408,18$ \\
São Benedito do Rio Preto & $27.167,74$ & 180,96 & $27.348,70$ \\
Urbano Santos & $7.372,71$ & $1.887,06$ & $9.259,77$ \\
\hline TOTAL & & & $\mathbf{2 2 8 . 9 5 8 , 0 0}$ \\
\hline
\end{tabular}

Fonte: DATALUTA-NERA-LAGEA, 2016. Org.: Soares et al. (2019).

Também há o argumento de que os atores sociais existentes naquelas terras por séculos têm o pleno direito do gozo de sua reprodução e usufruto. Pois os laços construídos por muitos anos, lhes trouxeram subsídio para sua territorialização, para a continuidade da reprodução campesina, para a continuidade de sua identidade como um ator social que pouco degrada, mantendo o meio como subsídio para sua existência, de forma a se inserir como parte dele e não fora dele (SAQUET, 2006).

Em suma, os resultados do trabalho reforçam a ideia de que a resistência dos camponeses além de trazer benefícios ambientais, também reforçam suas questões identitárias e reprodução social. Por outro lado, traz uma face perversa que são a dos conflitos violentos/criminais em que os próprios camponeses são as vítimas. Nesse sentido, nossas atenções deveriam estar focadas também na geografia da violência no campo (MELO; MATIAS, 2016), sobretudo para subsidiar políticas públicas de prevenção a conflitos territoriais e diminuição de impactos ambientais (MELO, 2017). 
Figura 7: Mapa de total de famílias assentadas da bacia do Rio Preto - MA

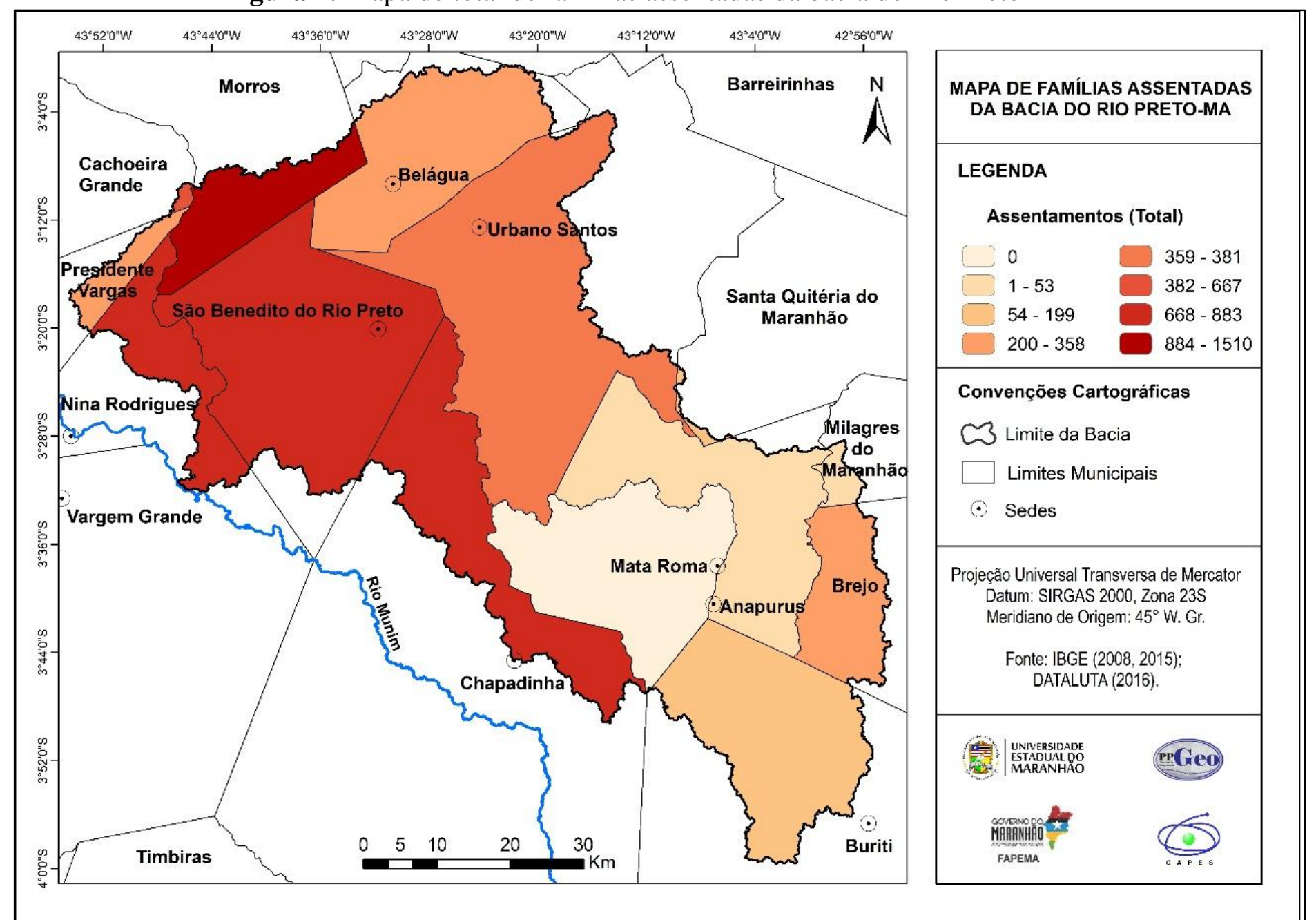

Org.: Soares et al., 2019. 


\section{Considerações finais}

O objetivo desse trabalho foi realizar uma análise dos conflitos territoriais e os impactos ambientais decorrentes das agroindústrias que se estabeleceram nos municípios banhados pela bacia hidrográfica do Rio Preto, Maranhão. Os resultados corroboram a ideia que os camponeses são desterritorializados do espaço onde construíram seus laços sociais em harmonia com o meio que lhe dão suporte para sua reprodução social, da sua cultura, dos seus costumes e valores, onde mantém seu modo de vida. Todavia, quando este espaço passa a ser cobiçado por outrem, neste caso específico, pelo agronegócio, os camponeses entram em conflito com estes, na busca da preservação do seu território, bem como da manutenção de sua territorialidade. Conclui-se também que as empresas voltadas para a produção de soja e de eucalipto, não somente estão causando impactos ao meio social, mas também ao meio ambiente e mais especificamente ao bioma cerrado que é encontrado na área de estudo.

Discutir os conflitos dos municípios que são drenados pela bacia do Rio Preto é de fundamental importância não só para área das ciências sociais, mas também para a sociedade, a qual precisa conhecer a dinâmica e a lógica do capitalismo perverso que é imposta ao camponês e ao meio ambiente. Assim, o camponês tem que ser visto como um ser social importante, que tem um papel relevante na sociedade, haja visto que estes são responsáveis por mais de $60 \%$ da produção de alimentos para o país e que emprega um expressivo contingente populacional no campo. Por tudo isso, devem ter direito ao acesso à terra e a manutenção de seu modo de vida, bem como a garantia de proteção contra investidas violentas do agronegócio e o amparo de políticas públicas de prevenção.

\section{Agradecimentos}

Os autores expressam seu agradecimento a Fundação de Amparo à Pesquisa e ao Desenvolvimento Científico e Tecnológico do Maranhão (FAPEMA), pelo financiamento do projeto de pesquisa intitulado: Análise da dinâmica do uso da terra na bacia hidrográfica do Rio Preto-MA, a Coordenação de Aperfeiçoamento de Pessoal de Nível Superior (CAPES) pelo financiamento do Projeto PROCAD/Amazônia intitulado: Uso do Território, 
Modernizações, Desigualdades Sociais e Questão Ambiental no Maranhão e ao Programa de Pós-Graduação em Geografia da Universidade Estadual do Maranhão (UEMA).

\section{REFERÊNCIAS}

ALMEIDA, J. G.; SODRÉ, R. B.; MATTOS JÚNIOR, J. S. O Matopiba nas Chapadas Maranhenses: Impactos da Expansão do Agronegócio na Microrregião de Chapadinha. REVISTA NERA, São Paulo, n. 47, p. 248-271, 2019.

BOTELHO, A. C.; ALMEIDA, J. G.; FERREIRA, M. G. R.O avanço dos "eucaliptais": análise dos impactos socioambientais em territórios camponeses no Leste Maranhense.

Revista Percurso, Maringá, v.4, n.2, p. 79-94, dez. 2012.

BOTELHO, A. C.; DINIZ, J. S. A produção da soja em territórios tradicionais da agricultura familiar na Microrregião de Chapadinha maranhão. In: ENCONTRO NACIONAL DE GEOGRAFIA AGRÁRIA. 21., 2012, Uberlândia, Anais [...]. Minas Gerais: LAGEA, 2012, p.1-12.

COMISSÃO PASTORAL DA TERRA - CPT. Relatório Conflitos no campo - Brasil 2016. Goiânia, 2016. 232p.

COSTA, F. A. Formação agropecuária da Amazônia: os desafios do desenvolvimento sustentável. Belém: Núcleo de Altos Estudos Amazônicos, Universidade Federal do Pará, 2000, 355p.

COSTA, F. A.; CARVALHO, H. M. de. Campesinato. In: CALDART, R. S. (org.). Dicionário da Educação do Campo. Rio de Janeiro, São Paulo: Escola Politécnica de Saúde Joaquim Venâncio, Expressão Popular, 2012. 788p. Verbete.

FERNANDES, B. M. A formação do MST no Brasil. 2. ed. Petrópolis: Editora Vozes, 2000. 316p.

FERNANDES, B. M. DATALUTA-Banco de Dados da Luta pela Terra. REVISTA NERA, n. 3, p. 7-27, 2012.

GASPAR, R. B.; REGO, J. L.; PAULA ANDRADE, M. P. Mobilização e justiça ambiental: Resistência camponesa e as transformações agrárias no Médio Mearim e Leste Maranhense. In: REUNIÃO BRASILEIRA DE ANTROPOLOGIA, 26., 2008, Porto Seguro, Bahia. Anais [...]. Brasília: ABA, 2008. p.1-11.

LIMA, F. L. S.; LOCATEL, C. D.; SILVA, C. C. L. In: ENCONTRO NACIONAL DE GEOGRAFIA AGRÁRIA, 21., 2012, Uberlândia - MG, Modernização seletiva da Agricultura: o avanço do agronegócio da soja no sul do Maranhão. Uberlândia: UFU, 2012. 
MELO, S. N.; MATIAS, L. F. Geografia do Crime e da Violência no Brasil entre 2007 a 2015. Revista da ANPEGE, v. 12, n. 19, p. 146-165, jul./dez. 2016.

MELO, S.N. Geografia do crime - Análise espacial da criminalidade no município de Campinas - SP. 2017. 219 f. Tese (Doutorado em Geografia) - Instituto de Geociências, Universidade Estadual de Campinas. Campinas, 2017.

MINISTÉRIO DO MEIO AMBIENTE - MMA. O Bioma Cerrado. Disponível em: http://www.mma.gov.br/biomas/cerrado. Acesso em: 15 jan. 2018.

MOTTA, M. Posseiro. In: MOTTA, M. (org.). Dicionário da terra. Rio de Janeiro: Civilização Brasileira, 2005. 373p. Verbete.

NASCIMENTO, S. M. V. Mulheres rurais e agroecologia: perdas e ganhos de um aprendizado cotidiano nas chapadas do Leste Maranhense frente à expansão da monocultura de soja. Revista Gênero, Niterói, v.15, n.1, p.81-102, 2.sem. 2014.

NASCIMENTO, S. M. V. Perda e (ganhos?): a memória feminina reconstruindo a história, antes e depois da implantação da monocultura de soja no município de Brejo no Maranhão. In: ENCONTRO DA SOCIEDADE BRASILEIRA DE SOCIOLOGIA DA REGIÃO NORTE, 2., 2010, Belém, Anais [...]. Belém: SBS norte, 2010. p.3-20.

OLIVEIRA, A. B. Indústria de celulose e o avanço da silvicultura do eucalipto na fronteira agrícola da Amazônia maranhense. Geosul, Florianópolis, v. 34, n. 71, p. 301327, abr. 2019.

PAULA ANDRADE, M. de. A produção de carvão vegetal e o plantio de eucalipto no Leste Maranhense. In: Carajás: desenvolvimento ou destruição? Relatórios de pesquisa. São Luís: CPT, 1995, p.15-65.

PAULA ANDRADE, M. de. A Suzana - o cerco das terras camponesas e a destruição dos recursos naturais pela Suzano Papel e Celulose. In: ENCONTRO ANUAL DA ANPOCS, 35., 2011, Caxambu - MG, Anais [...]. Caxambu: ANPOCS, 2011. p.1-19.

PAULA ANDRADE, M. de. Os gaúchos descobrem o Brasil: projetos agropecuários contra a agricultura camponesa. São Luís: EDUFMA, 2008.

PEREIRA, V. L. G.; ROCHA, V. P. S.; BONACIM, C. A. G. Corredor de Exportação Norte e a viabilidade pela logística de transporte. Nucleus, São Paulo, v.5, n.2, p.161172, out. 2008.

PRESOTI, A. E. P. Avaliação de impactos ambientais da sojicultura em um ecossistema aquático da Microrregião de Chapadinha, MA. 2008. 117 f. Dissertação (Mestrado em Sustentabilidade de Ecossistemas) - Universidade Federal do Maranhão, São Luís, 2008.

RIBEIRO JÚNIOR, J. A. S. R.; OLIVEIRA, D. M. V.; COSTA, S. B. da. Desenvolvimento, conflitos e impactos ambientais: a territorialização da Suzano e a 
resistência camponesa na Mesorregião Leste Maranhense. Revista Geographia Opportuno Tempore, Londrina, v.1, n.2, p.11-33, jul./dez. 2014.

RIBEIRO, A. C. T. Território brasileiro: usos e abusos - Pequena reflexão sobre categorias da teoria crítica do espaço: território usado, território praticado. In: Por uma sociologia do presente: ação, técnica e espaço. v. 3. Rio de Janeiro: Letra Capital, 2013. p.141-152.

RODRIGUES, V. V.; TERRA, A. O Drama Camponês no Cerrado Sul Maranhense: conflitos socioterritoriais no campo em Balsas. CAMPO-TERRITÓRIO: revista de geografia agrária, v. 13, n. 31, p. 191-207, dez. 2018.

SANTOS, C. C. M. Programa de Cooperação Nipo-Brasileira para o Desenvolvimento dos Cerrados - PRODECER: um espectro ronda os cerrados brasileiros. Estudos Sociedade e Agricultura, Rio de Janeiro, v. 24, n. 2, p.385-416, out. 2016.

SANTOS, M. A natureza do espaço: técnica e tempo, razão e emoção. São Paulo: Hucitec, 1996. 308p.

SANTOS, M. O retorno do território. In: OSAL: Observatorio Social de América Latina. Ano 6, n. 16 (jun. 2005-). Buenos Aires: CLACSO, 2005.

SANTOS, N. A. dos. A divisão sexual do trabalho na agricultura familiar: entre a invisibilidade e a desvalorização do trabalho (re)produtivo de mulheres trabalhadoras rurais do município de Brejo/MA frente à expansão da monocultura de soja. Revista de Políticas Públicas, São Luís, v. 20, Número Especial, p.331-337, nov. 2016.

SAQUET, M. A. Campo-território: considerações teórico-metodológicas. CAMPOTERRITÓRIO: revista de geografia agrária, Uberlândia, v. 1, n. 1, p. 60-81, fev. 2006.

SODRÉ, R. B.; ALMEIDA, J. G.; SOUSA, I. B. B.; SOUZA, T. A. S.; MATTOS JÚNIOR, J. S. As faces do agronegócio maranhense: uma análise da expansão agrícola e do aumento da violência no campo. Geosul, Florianópolis, v. 34, n. 71, p. 599-622, abr. 2019.

VAN DER PLOEG, J. D. Sete teses sobre a agricultura camponesa. In: Agricultura familiar camponesa na construção do futuro. Rio de Janeiro: ASPTA, 2009. p. 1732.

Recebido em 03/04/2020.

Aceito para publicação em 17/09/2020. 